\title{
Two Randomized, Double Blind, Placebo- Controlled Trials Evaluating the Efficacy of Red 635nm Low Level Laser for the Treatment of Low Back Pain
}

\author{
Trevor S Berry ${ }^{1}$, Travis M Sammons ${ }^{2}$ and Steve Shanks ${ }^{2}$ \\ ${ }^{1}$ Arizona Chiropractic Neurology Center. Chandler, $A Z$ \\ ${ }^{2}$ Erchonia Corporation, Melbourne, FL, USA
}

Submission: January 05, 2021; Published: January 15, 2021

*Corresponding author: Travis M Sammons, Erchonia Corporation, Melbourne, FL USA

\begin{abstract}
Objectives: Low back pain (LBP) is the global leading cause of disability with over eighty percent of the population experiencing an episode of LBP. A new emerging technology, low-level laser therapy (LLLT) has demonstrated promising results for the treatment of various chronic musculoskeletal conditions. The objective of the following review was to analyze data from two separate double-blind placebo-controlled trials using red $635 \mathrm{~nm}$ low-level laser for the treatment of chronic low back pain.
\end{abstract}

Materials and Methods: Subjects $(n=120)$ were males and females, ages 18 years or older with episodic chronic low back pain of at least 3 months duration. Subjects received eight laser treatments to the lower back region consisting of two procedures per week, 3 to 4 days apart. The low-level laser device contained three independent $17 \mathrm{~mW}, 635 \mathrm{~nm}$ red laser diodes (Erchonia ${ }^{\circledR}$ FX-635 ${ }^{\mathrm{Tm}}$; Erchonia Corporation, Melbourne, FL). The primary efficacy assessment was the change in visual analog scale (VAS) pain scores. The predefined outcome measure was the proportion of subjects achieving a $\geq 30 \%$ change in VAS pain scores at a 2 -month follow-up assessment. Overall study success was predefined as a $\geq 35 \%$ between-group difference in the proportion of subjects achieving treatment success.

Results: $80 \%$ of subjects treated with the low-level laser achieved a $\geq 30 \%$ decrease in low back pain VAS scores vs. $28 \%$ of placebo-treated subjects ( $52 \%$ difference; $\mathrm{p}<0.00001)$. The mean decrease in low back pain VAS scores was 36.59 points for subjects treated with the laser vs. 8.70 points for placebo-treated subjects (27.89-point difference; $\mathrm{p}<0.0001)$.

Conclusion: The data demonstrates the clinical utility of low-level laser for treatment of LBP. Based on efficacy and safety, $635 \mathrm{~nm}$ red laser has received Food and Drug Administration (FDA) market clearance for use to provide relief of minor chronic low back pain. (K180197).

Keywords: Low-level laser therapy; Low back pain; Chronic pain; Clinical trial; Laser pharmacology

\section{Introduction}

Low back pain (LBP) is the global leading cause of disability with over 80 percent of the population experiencing an episode of LBP at some time during life [1]. An estimated 264 million days of work per year are lost due to LBP [2]. The condition also presents a major challenge to United States health system, with total costs estimated to be between 100-200 billion dollars annually, twothirds of which are due to decreased wages and productivity [3]. The point prevalence has been shown to increase with advancing age, from $4.2 \%$ among individuals 24 to 39 years old to $19.6 \%$ among those 20 to 59 years old [4]. It is among the ten leading causes of years lived with disability in every country surveyed [5]. In the United States, LBP has a point prevalence of approximately $12 \%$, a 1-month prevalence of $23 \%$, a 1 -year prevalence of $38 \%$ and a lifetime prevalence of $40 \%$ [6]. Among all types of disorders in the United States, low-back pain ranks third for disabilityadjusted life-years and first by years lived with disability [7]. One common treatment for LBP, is the use of Non-steroidal antiinflammatory (NSAID) drugs. For acute LBP, traditional NSAIDs do reduce pain, without any clear evidence that one agent is superior to another [8]. However, NSAID treatment should be used for the shortest time at the lowest dose that achieves adequate pain 
relief [8]. Short-term use of NSAIDs is appropriate in most cases of acute LBP [8]. The toxicities of chronic NSAID administration are concerning, hence only a very small number of chronic LBP patients should use NSAIDs, besides an as needed basis [8]. The burden of toxicity from NSAIDs denies what had been the widely held perspective that NSAIDs are "safer" analgesics. Both Cox-1 and Cox- 2 inhibitors have adverse drug reactions in both the short term and the long term. It has been reported that as many as 107,000 hospitalizations and 16,500 deaths annually in the United States may be attributable to NSAID toxicity [9]. Through the 1990s it was suggested that for every dollar spent on NSAIDs, treatment of NSAID toxicity cost \$1.25 [10].

In meta-analysis of 35 randomized placebo-controlled trials, [11] NSAIDs reduced spinal pain and disability but provided clinically unimportant effects over placebo. For one participant to achieve clinically important pain reduction, six participants are needed to be treated with NSAIDs, rather than placebo [11]. Opioids appear to have short-term efficacy for treating chronic LBP with much less evidence supporting long-term use [12], possibly due to tolerance [13], and may not provide additional benefits over the use of NSAIDS alone [14]. Half of patients treated with opioids discontinue using them due to lack of efficacy or adverse events [15], including constipation, nausea, sedation addiction, and overdose-related mortality [12].

Noninvasive, drug-free treatments for LBP are becoming more prevalent and recommended. The American College of Physicians (ACP) developed a guideline to present evidence and provide clinical recommendations on noninvasive treatment of low back pain [16].Included in the list of strong recommendations is the use of low-level laser therapy [16]. In addition, low-level laser became more recognized option for LBP in 2018 when The Food and Drug Administration (FDA) cleared the first laser device (Erchonia ${ }^{\circledR}$ FX-635 $5^{\mathrm{TM}}$ ) as an adjunct to provide relief of minor chronic low back pain of musculoskeletal origin (K180197) [17]. The treatment administered red $635 \mathrm{~nm}$ non-thermal laser. The objective of the following review is to analyze data from two separate doubleblind placebo-controlled studies totaling 120 subjects assessing the improvement in chronic low back pain following treatment of the red $635 \mathrm{~nm}$ nonthermal laser.

\section{Methods}

Data is compiled from two IRB-approved clinical trials which included four different independent investigator test sites. Both clinical trials were double-blind, placebo-controlled design. A computer program was used to perform the participant group assignment. The double-blind component of the study was established by including a treatment investigator and an assessment investigator. The treatment investigator was responsible for administering the active and placebo interventions. That investigator was the only individual present in the room during the treatment phase and did not participate in the pre- or post-treatment evaluation activities. The assessment investigator was responsible for conducting the pre- and post-procedure evaluations and determining the diagnosis and eligibility of the participants for study participation. The assessment investigator was never aware of the participants' group allocation. Additionally, the study participants were never informed of their group assignment and wore darkened protective glasses designed to filter out the laser light during the treatment procedure.

Study subjects were male or female, $\geq 18$ years old and recruited from among each investigators' pool of patients and individuals responding to local recruitment flyers and print ads. Qualifying subjects received financial compensation for completed study compliance and participation. Low back pain was of musculoskeletal origin involving lumbar sprain, strain or stretch injury to the ligaments, tendons, and/or muscles of the low back in the absence of nerve root compromise. Each subject was required to have primary pain located in the left, right or both sides of the lower back, defined as the area between the lowest rib and the crease of the buttocks. Diagnosis included a history of initial LBP onset occurring after one or more of the following events: known injury, such as an accident or fall; overexertion of a muscle, such as after unusual amounts of exercise or unaccustomed activity, or sustained positioning (strain injury); or sudden force or movement exerted upon ligaments, such as unusual turning or twisting (sprain injury). Subjects experienced at least two of the following: pain and/or loss of function such as inability to turn, twist or bend normally; pain located along lower back and upper buttocks which may radiate into surrounding tissue; pain that worsens with activity; painful muscle spasms that can worsen with activity or at night while asleep; or history of prior back injury.

Diagnosis was further based on a physical examination which revealed at least three of the following features: inability or difficulty straightening into normal posture while standing; activities such as sitting, standing, walking or driving are limited, difficult or impossible; palpation of muscles in lower lumbar area reveals local tenderness and muscle spasm while lying in prone position; change in sensation and/or motor function of knees and ankles; raising straight leg from supine position produces sciatica; or upon observation, there is no notable posture, spinal alignment or other back deformities. The LBP was chronic, defined as ongoing over $\geq 3$ preceding months, with pain having occurred on $\geq 15$ days of each preceding month, and each episode lasting $\geq 24$ hours followed by a subsequent period of $\geq 24$ hours without pain. Other inclusion criteria included a self-reported score of $\geq 40$ on the 100-point Visual Analog Scale (VAS) pain scale; ability to refrain from consuming analgesic, anti-inflammatory or muscle relaxing medications throughout the study except for the studyrelated pain relief medication; refraining from other therapies for managing LBP, such as physical therapy, occupational therapy and hot or cold packs, chiropractic care or acupuncture; and ability to complete a daily patient diary. 


\section{Orthopedics and Rheumatology Open Access Journal (OROAJ)}

Subjects with LBP known to be caused by the following etiologies were excluded from study participation: mechanical (apophyseal osteoarthritis, thoracic or lumbar spinal stenosis, spondylolisthesis), inflammatory (ankylosing spondylitis, rheumatoid arthritis, infection), neoplastic (primary or metastatic bone tumors, intradural spinal tumors), metabolic (osteoporotic fractures, osteomalacia, chondrocalcinosis) or psychosomatic conditions (tension myositis syndrome). Other exclusion criteria included the use of the muscle relaxants cyclobenzaprine, diazepam or meprobamate within the prior 30 days, use of the muscle relaxants carisoprodal or metaxalone within the prior 7 days, initiation of the antidepressants duloxetine or a tricyclic or serotonin-selective reuptake inhibitor within the prior 30 days, systemic corticosteroid therapy or narcotics within 30 days; infection, wound or other external trauma to the planned treatment area; prior back or spine surgery; history of alcohol or other substance abuse; pregnancy, breast feeding, or planning pregnancy prior to the end of the study; participation in a clinical study or other type of research during the past 30 days.

\section{Intervention}

The low-level laser device used in this study was comprised of three independent $17 \mathrm{~mW}, 635 \mathrm{~nm}$ red laser diodes mounted in a scanner device with flexible arms (Erchonia ${ }^{\circledR}$ FX-635 ${ }^{\mathrm{TM}}$; Erchonia Corporation, Melbourne, FL). The device utilizes internal mechanics that collects light emitted from each laser diode that is processed through a proprietary patented lens which redirects into a line generated beam. The device then applies the line laser light into a spiraling circle pattern that is totally random and independent of the other diodes. The device delivers 10.2 joules to each of the three treated areas consisting of the lower spine and both hip flexors. As the device mechanically scans the three areas simultaneously, the estimated amount of total energy delivered is $0.0865 \mathrm{~J} / \mathrm{cm}^{2}$. The placebo group participants were treated using the same multi-head device, however the placebo group instead received treatment from light-emitting diodes (LED), which produced noncoherent light of the same color when activated. Eye protection was provided for use by the investigator and the subject (Laser Safety Industries; St. Paul, MN).

\section{Procedures}

Eligible subjects entered a 2-day pretreatment Washout Phase and abstained from non-study related medications for low back pain and began using the as-needed study rescue medication acetaminophen $325 \mathrm{mg}$ tablets (Tylenol $^{\circledR}$; McNeil Consumer Healthcare, Fort Washington, PA) which continued until the end of the post-treatment evaluation phase. Upon waking on these 2 days, subjects recorded their pain severity using the 0-100 VAS scale and completed the daily diary documenting study compliance. Subjects were then randomized to receive treatment with the active or placebo light in double-blind fashion. Each subject received eight 20-minute treatments applied to the lower back region with their assigned treatment group over a consecutive 4-week period consisting of two procedures per week, 3-4 days apart. Each procedure administration occurred at the investigator's test site.

\section{Outcome Measures}

The pain severity was assessed using a 0-100 Visual Analog Scale (VAS). The VAS is a $100 \mathrm{~mm}$ horizontal line on which the patient's pain intensity is represented by a point between the extremes of "no pain at all" and "worst pain imaginable". The VAS is widely used across a broad range of populations and clinical settings and has been well-accepted as a generic pain measure for many years [18]. VAS evaluation was completed within ten minutes following each study procedure and repeated at study endpoint 2-months post-treatment. The following analysis is based on the change in mean pre-treatment subject VAS scores at study endpoint.

\section{Efficacy Endpoint}

The aim of each of these studies was to determine if the treatment effect of the Erchonia laser device for the active treatment group was more effective than placebo treatment for alleviating LBP. The Primary efficacy outcome measure was predefined as the difference in the proportion of subjects between test and control groups who achieved a clinically meaningful and statistically significant decrease in self-reported VAS low back pain rating of $30 \%$ or greater at study endpoint relative to baseline. The clinical relevance of a 30\% change in VAS score was previously established by the U.S. Food and Drug Administration Division of Surgical, Orthopedic and Restorative Devices through numerous pre-investigational device exemption (IDE) reviews. Overall study success was predefined as at least a $35 \%$ difference in the proportion of individual subject successes between procedure groups.

\section{Statistical Analysis}

At-test for independent samples was used to analyze betweengroup differences in demographics and baseline characteristics. A Fischer's Exact Test for two independent proportions was used to analyze primary efficacy, and an ANCOVA analysis was used to analyze the mean change in low back pain VAS scores. As every randomized subject completed all study visits and procedures and had all study measurements recorded through the final evaluation, only an intent-to-treat analysis was performed for primary outcome success.

\section{Ethics}

The study protocols and related materials were approved by a commercial institutional review board (Western Institutional Review Board, Olympia, WA; IRB number 20120787 and 20151815) and conformed to the good Clinical Practice guidelines of the International Conference on Harmonization. All subjects provided signed informed consent prior to participating in any study-related activities. 


\section{Orthopedics and Rheumatology Open Access Journal (OROAJ)}

\section{Results}

\section{Demographics}

The 120 participating subjects were randomized to the active $(n=60)$ and placebo treatment groups $(n=60)$. All subjects completed the study according to protocol. Demographics and baseline characteristics of enrolled subjects are summarized in Table 1. A t-test for independent samples revealed no statistically significant between-group differences for any parameter.

Table 1: Demographics and Baseline Characteristics.

\begin{tabular}{|c|c|c|}
\hline & $\begin{array}{c}\text { Test } \\
(\mathbf{n = 6 0}\end{array}$ & $\begin{array}{c}\text { Placebo } \\
(\mathbf{n = 6 0})\end{array}$ \\
\hline Mean Age, years (SD) & $49.4(15.2)$ & $48.0(15.14)$ \\
\hline Gender & & \\
\hline Male & 28 & 32 \\
\hline Female & 32 & 28 \\
\hline Race/Ethnicity & & \\
\hline Caucasian & 50 & 42 \\
\hline Hispanic & 3 & 10 \\
\hline African American & 4 & 5 \\
\hline Asian & 3 & 3 \\
\hline $\begin{array}{c}\text { Mean Pain Duration, } \\
\text { months (SD) }\end{array}$ & $89.5(87.9)$ & $93(96.7)$ \\
\hline
\end{tabular}

\section{Primary Efficacy Measure}

At the end of the study, $80 \%$ of subjects treated with low level laser achieved $\mathrm{a} \geq 30 \%$ decrease in baseline LBP VAS scores vs. $28 \%$ of subjects treated with the placebo device, a difference of $52 \%(p<0.00001)$. The mean decrease in LBP VAS scores was 36.59 points for subjects treated with the laser vs. 8.70 points for subjects treated with the placebo device, a difference of 27.89 points $(p<0.001)$ (Table 2 and Chart 1$)$.

Table 2: Baseline and Endpoint VAS by Treatment Group.

\begin{tabular}{|c|c|c|c|c|}
\hline & \multicolumn{2}{|c|}{ Test Group (n=60) } & \multicolumn{2}{c|}{ Placebo Group $(\mathbf{n = 6 0})$} \\
\hline & Mean & SD & Mean & SD \\
\hline Baseline & 60.15 & 12.51 & 57.50 & 12.00 \\
\hline Endpoint & 23.56 & 22.84 & 48.80 & 23.13 \\
\hline Change & -36.59 & 21.02 & -8.70 & 20.56 \\
\hline
\end{tabular}

\section{Primary Safety Measure}

No adverse events were reported by any subject throughout the duration of the study.

\section{Visual Analog Scale Low Back Pain Scores}

Among subjects treated with LLLT, there was a progressive and substantial decrease in mean LBP VAS scores throughout the duration of the study (Chart 1). In contrast, there was a small decrease in VAS scores among placebo-treated subjects which was not clinically meaningful.

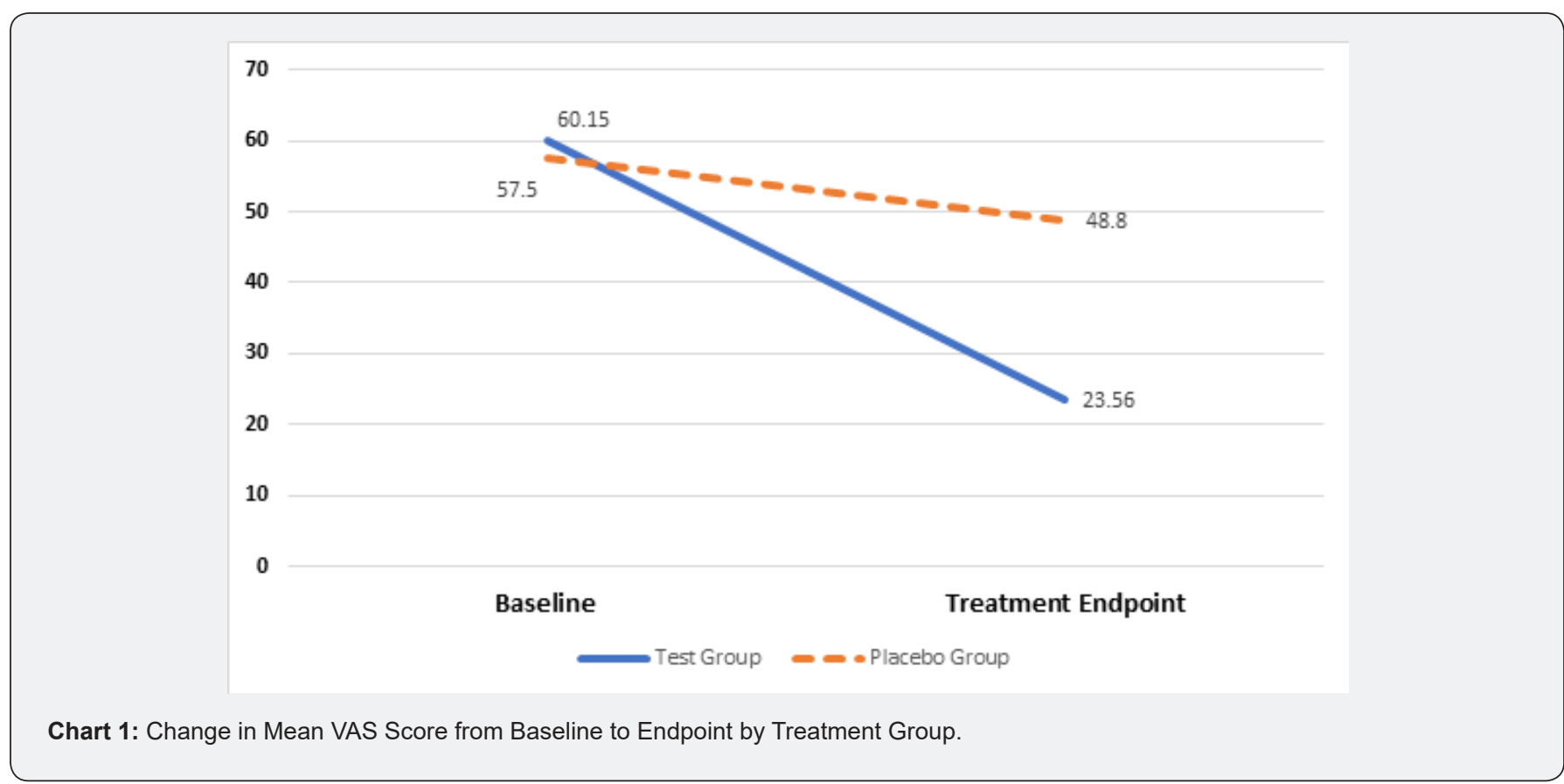

\section{Subject Satisfaction}

Subjects rated their satisfaction with the change in LBP at the study endpoint. Using the 5-point Likert scale in response to the question "Overall, how satisfied or dissatisfied are you with any change in the pain in your lower back following the study procedures with the study laser device?," 47 subjects randomized to active treatment were satisfied vs. 19 placebo-treated subjects (Table 3). 


\section{Orthopedics and Rheumatology Open Access Journal (OROAJ)}

Table 3: Category of Satisfaction Responses by Treatment Group.

\begin{tabular}{|c|c|c|}
\hline & Test group (n=60) & Placebo group (n=60) \\
\hline & $\mathbf{n}(\%)$ & $\mathbf{n}(\mathbf{\%})$ \\
\hline Very satisfied & $31(52 \%)$ & $6(10 \%)$ \\
\hline Somewhat satisfied & $16(27 \%)$ & $13(22 \%)$ \\
\hline $\begin{array}{c}\text { Neither satisfied } \\
\text { nor dissatisfied }\end{array}$ & $9(15 \%)$ & $20(33 \%)$ \\
\hline Not very satisfied & $3(5 \%)$ & $13(22 \%)$ \\
\hline Not at all satisfied & $1(1 \%)$ & $8(13 \%)$ \\
\hline
\end{tabular}

\section{Discussion}

The process of LLLT is based on a photochemical reaction in which discrete units called photons are absorbed within the visible spectrum (380-700 nm). The photon-induced chemistry ultimately gives rise to the observable effect at the biological level [19]. If light of a particular wavelength is not absorbed by a system, no photochemistry will occur, and no photobiological effects will be observed, no matter how long one irradiates with that wavelength of light [20]. The wavelength used in this review was $635 \mathrm{~nm}$ (red) laser which is in the visible light spectrum.

The enzyme, cytochrome c oxidase (CCO) has been shown to be activated in vitro by red laser (633 nm) [21]. Therefore, optimal biological stimulation can be achieved utilizing a device that emits light within the red spectrum. UV and visible light are absorbed by proteins and pigments, whereas the absorption of infrared light can be attributed to water molecules [22]. Water has a narrow window of transparency which includes the visible light spectrum (400-700nm) [23]. There is no physical mechanism which produces transitions in the visible light spectrum, as it is too energetic for the vibrations of the water molecule and below the energies needed to cause electronic transitions [23]. The infrared light spectrum exhibits strong absorption from vibrations of the water molecule. The result of infrared absorption is heating of the tissue since it increases molecular vibrational activity [23]. Infrared radiation does penetrate the skin further than visible light. ${ }^{23}$ The primary mechanism for the absorption of visible light photons is the elevation of electrons to higher energy levels [23]. Simply, while visible light can produce photochemical effects, infrared only produces molecular rotations and vibrations [24]. The benefits of infrared wavelengths on low back pain are still unsubstantiated. One study showed that infrared laser combined with exercise is more beneficial than exercise alone for chronic low back, however there was no difference in the laser group alone and the placebo laser after six weeks of invervention [25]. A systematic review of twelve randomized controlled studies all emitting infrared wavelengths on pain associated with nonspecific low back pain [26], concluded that the current evidence does not support the use of laser to decrease pain and disability in people with non-specific LBP. Another type of light source being marketed for low back pain is light emitting diode (LED).
Based on the outcomes in the two reviewed double-blind placebocontrolled studies, in which the placebo group received LED treatment, it can be concluded that laser is superior to LED in reducing pain associated with low back pain and should be the first line of therapy. Currently there are no FDA cleared infrared lasers or light emitting diodes for low back pain.

The intracellular effects generated by the absorption of $635 \mathrm{~nm}$ irradiation are responsible for the reduction of inflammatory phase and the expression of genes involved in tissue repair. These changes are defined as Laser Pharmacology ${ }^{\mathrm{TM}}$ which describes the discipline in which a series of interactions caused by Erchonia laser photons produce a change in physiology, through similar if not the same biological pathways of pharmaceutical drugs. The mechanism of action is completely nonthermal.

Following trauma to the low back, the inflammation phase is formed by the enzyme Cyclooxygenase-2 (COX-2). Inhibition of cyclooxygenase (Cox) and prostaglandin E2 (PGE2) protects cells against injury from inflammation and oxidative stress, which is the most likely mechanism of action for NSAID-mediated analgesia [27]. Comparable effects have been documented following exposure to red LLLT were a significant reduction in COX-2 mRNA expression was found in the sub plantar $(\sim 2.5$-fold $)$ and brain (4.84-9.67-fold) tissues [28]. Normally, lesion-induced pain subsides and does not develop into chronic pain. A probable factor in the pathophysiology of low back pain and the transition to a chronic state is considered to be due to the lack of nitric oxide (NO) [29]. Irradiation of $635 \mathrm{~nm}$ laser has shown to produce a significant upregulation of iNOS after a single treatment of post inflammation induction, whereas other wavelengths $(785,808$ and $905 \mathrm{~nm}$ ) were not significantly different from the control group [30]. Considering the low quantum energy per photon for the 785 to $905 \mathrm{~nm}$ range, equal to 1.52 to $1.37 \mathrm{eV}$, they apparently do not induce direct photochemistry as the minimum quantum energy for cis-trans isomerization is on the order of $1.7 \mathrm{eV} \mathrm{[30].}$

The modulation of transcription factors has become a common therapeutic strategy to prevent or provoke the expression of specific genes, and the approach could potentially provide a means to treat a wide assortment of medical disorders. Red laser can play a direct role in gene expression by first stimulating cytochrome $\mathrm{C}$ oxidase which accelerates the electron transport leading to increased ATP production [31,32]. At the same time, this photochemistry is linked to the generation of ROS [33]. In higher concentrations ROS can be cytotoxic, however, in lower concentrations it can result in the activation of various transcription factors such as NF-kB33, AP-133, and HSP33, which increases signaling pathway and gene expression leading to increased protein synthesis [33], and cell homeostasis [34]. A substantial amount of evidence has been published that supports the theory that laser irradiation within the red spectrum does play a unique role in the expression of specific genes. Perhaps the most significant was Zhang et al. who used cDNA microarray technique to investigate the gene expression profiles of human 
fibroblasts irradiated by low-intensity red light [35]. The gene expression profiles revealed that 111 genes were regulated by the red-light irradiation and can be grouped into 10 functional categories [35]. The affected genes were related to cell growth, collagen production, microcirculation, antiapoptotic, DNA repair, and antioxidation.

\section{Conclusion}

Based on the data of 120 subjects, the use of red $635 \mathrm{~nm}$ non-thermal laser is an effective means for reducing episodic chronic low back pain of musculoskeletal origin. At the end of the study, most subjects treated with the low-level laser (80\%) achieved a $\geq 30 \%$ decrease in baseline LBP VAS scores vs. $28 \%$ of subjects treated with the placebo device. In addition, one of the reviewed studies documented changes in the Oswestry disability index, which demonstrated a clinically meaningful improvement in the LLLT treated group [36]. Although additional studies are warranted, the noninvasive nature of laser therapy enables this technology to serve as a primary treatment of chronic low back pain.

\section{Acknowledgment}

The studies were sponsored by Erchonia Corporation, Melbourne, FL. As the study sponsor, Erchonia was responsible for device setup and training. The studies were performed at independent physician sites, which completed CITI training (Collaborative Institutional Training Initiative) and approved through the Western Institutional Review Board (WIRB). Statistical analysis of the clinical data was performed by Regulatory Insight, Inc. Elvira Walls, MS, who was the independent statistician for this clinical investigation.

\section{References}

1. Freburger JK, Holmes GM, Agans RP, Anne M Jackman, Jane D Darter, et al. (2009) The rising prevalence of chronic low back pain. Arch Intern Med 169(3): 251-258.

2. The Hidden Impact of Musculoskeletal Disorders on Americans, United State Bone and Joint Initiative, 2018.

3. Katz JN (2006) Lumbar disc disorders and low-back pain: socioeconomic factors and consequences. J Bone Joint Surg Am 88(Suppl 2): 21-24.

4. Meucci, Rodrigo Dalke, Fassa, Anaclaudia Gastal, Faria, et al. (2015) Prevalence of chronic low back pain: systematic review. Revista de Saúde Pública 49: 1.

5. Global Burden of Disease Study 2013 Collaborators (2015) Global, regional, and national incidence, prevalence, and years lived with disability for 301 acute and chronic diseases and injuries in 188 countries, 1990-2013: a systematic analysis for the Global Burden of Disease Study 2013. Lancet 386(9995): 743-800.

6. Manchikanti L, Singh V, Falco FJ, Benyamin RM, Hirsch JA (2014) Epidemiology of low back pain in adults. Neuromodulation 17 Suppl 2: 3-10.

7. Violante FS, Mattioli S, Bonfiglioli R (2015) Low-back pain. Handb Clin Neurol 131: 397-410.
8. Kuritzky L, Samraj GP. Nonsteroidal anti-inflammatory drugs in the treatment of low back pain. J Pain Res 5: 579-590.

9. Moore N, Pollack C, Butkerait P (2015) Adverse drug reactions and drug-drug interactions with over-the-counter NSAIDs. Ther Clin Risk Manag 11: 1061-1075.

10. Abramson SB, Weaver AL (2005) Current state of therapy for pain and inflammation. Arthritis Res Ther 7(Suppl 4): S1-S6.

11. Machado GC, Maher CG, Ferreira PH, Richard O Day, Marina B Pinheiro, et al. (2017) Non-steroidal anti-inflammatory drugs for spinal pain: a systematic review and meta-analysis Annals of the Rheumatic Diseases 76(7): 1269-1278.

12. Abdel Shaheed C, Maher CG, Williams KA, Day R, McLachlan AJ (2016) Efficacy, tolerability, and dose-dependent effects of opioid analgesics for low back pain: a systematic review and meta-analysis. JAMA Intern Med 176(7): 958-968.

13. Deyo RA, Von Korff M, Duhrkoop D (2015) Opioids for low back pain. BMJ 350: g6380.

14. Friedman BW, Dym AA, Davitt M, Holden L, Solorzano C, et al. (2015) Naproxen With cyclobenzaprine, oxycodone/acetaminophen, or placebo for treating acute low back pain: a randomized clinical trial. JAMA 314(15): 1572-1580.

15. Shaughnessy AF (2016) Opioid Analgesia Hard to Tolerate and Not Effective for Chronic Low Back Pain. Am Fam Physician 94(9): 753757.

16. Qaseem A, Wilt TJ, McLean RM, Forciea MA (2017) Clinical Guidelines Committee of the American College of Physicians. Noninvasive Treatments for Acute, Subacute, and Chronic Low Back Pain: A Clinical Practice Guideline From the American College of Physicians. Ann Intern Med 166(7): 514-530.

17. https://www.accessdata.fda.gov/cdrh_docs/pdf18/K180197.pdf

18. Hawker GA, Mian S, Kendzerska T, French M (2011) Measures of adult pain: Visual Analog Scale for Pain (VAS Pain), Numeric Rating Scale for Pain (NRS Pain), McGill Pain Questionnaire (MPQ), ShortForm McGill Pain Questionnaire (SF-MPQ), Chronic Pain Grade Scale (CPGS), Short Form-36 Bodily Pain Scale (SF-36 BPS), and Measure of Intermittent and Constant Osteoarthritis Pain (ICOAP). Arthritis Care Res (Hoboken) 11: S240-252.

19. Karu, T (2007) Ten Lectures on Basic Science of Laser Phototherapy. Grangesberg, Sweden: Prima Books AB.

20. Smith Kendic. The First law of Photochemistry and Lasers. Laser Therapy Vol 11-14.

21. Pastore D, Greco M, Passarella S (2000) Specific helium-neon laser sensitivity of the purified cytochrome c oxidase. Int J Radiat Biol 76(6): 863-870.

22. Alazzawi, Mohammed, Al-Kukash, Sarah, Zaidan A, Bahaa, et al. (2011) An Overview of Laser Principle, Laser-Tissue Interaction Mechanisms and Laser Safety Precautions for Medical Laser Users. International Journal of Pharmacology 7: 149-160

23. http://hyperphysics.phy-astr.gsu.edu/hbase/Chemical/watabs.html

24. Smith Kendric (2010) Molecular Targets for Low Level Light Therapy. Laser Therapy 19(3): 135-142.

25. Gholamreza Esmaeeli Djavid, Ramin Mehrdad, Mohammad Ghasemi, Hormoz Hasan-Zadeh, Akbar Sotoodeh-Manesh, et al. (2007) In chronic low back pain, low level laser therapy combined with exercise is more beneficial than exercise alone in the long term: a randomised trial, Aust J Physiother 53(3): 155-160. 
26. Shaiane Silva Tomazoni, Matheus Oliveira Almeida, Jan Magnus Bjordal, Martin Bjørn Stausholm, Caroline dos Santos Monteiro Machado, et al. (2020) Photobiomodulation therapy does not decrease pain and disability in people with non-specific low back pain: a systematic review, J Physiother 66(3): 155-165.

27. Cashman JN (1996) The mechanisms of action of NSAIDs in analgesia. Drugs 52 Suppl 5: 13-23.

28. Prianti AC Jr, Silva JA Jr, Dos Santos RF, Rosseti IB, Costa MS (2014) Low-level laser therapy (LLLT) reduces the COX-2 mRNA expression in both subplantar and total brain tissues in the model of peripheral inflammation induced by administration of carrageenan. Lasers Med Sci 29(4): 1397-403.

29. Mense S (2001) Pathophysiologie des Rückenschmerzes und seine Chronifizierung - Tierexperimentelle Daten und neue Konzepte [Pathophysiology of low back pain and the transition to the chronic state - experimental data and new concepts]. Schmerz 15(6): 413-417.

30. Yumi Moriyama, Eduardo H Moriyama, Kristina Blackmore, Margarete K Akens, Lothar Lilge (2005) "Inflammatory modulating effects of lowlevel laser therapy on iNOS expression by means of bioluminescence imaging," Proc. SPIE 5969, Photonic Applications in Biosensing and Imaging 81(6): 1351-1355.
31. Glazewski JB (2000) Low energy laser therapy as quantum medicine. Laser Therapy 12: 39-42.

32. Bertoloni G, Sacchetto R, Baro E, Ceccherelli F, Jori G (1993) Biochemical and morphological changes in Echerichia coli irradiated by coherent and noncoherent $632.8 \mathrm{~nm}$ light. J. Photochem Photobiol 18(2-3): 191-196.

33. Rai Vikrant (2016) Role of Reactive Oxygen Species in Low-Level Laser Therapy. Proceedings of SPIE.

34. Yu Sun, Yifan Lu, Jason Saredy, Xianwei Wang, Charles Drummer IV, et al. (2020) ROS systems are a new integrated network for sensing homeostasis and alarming stresses in organelle metabolic processes, Redox Biology 37: 101696.

35. Zhang Yaou, Song Shipeng, Fong Chi-Chun, Tsang Chi-Hung, Yang Zhong, et al. (2003) cDNA Microarray Analysis of Gene Expression Profiles in Human Fibroblast Cells Irradiated with Red Light. The JoJ Invest Dermatol 120(5): 849-857.

36. Berry TS, Quarneri PJ, Sammons TM (2020) A Randomized, DoubleBlind, Sham-Controlled Study Evaluating the Effectiveness of a Lowlevel Laser Device for Treating Lower Back Pain. eMedical Res 2: 1000.

\section{Your next submission with Juniper Publishers will reach you the below assets}

- Quality Editorial service

- Swift Peer Review

- Reprints availability

- E-prints Service

- Manuscript Podcast for convenient understanding

- Global attainment for your research

- Manuscript accessibility in different formats

( Pdf, E-pub, Full Text, Audio)

- Unceasing customer service

Track the below URL for one-step submission https://juniperpublishers.com/online-submission.php 
